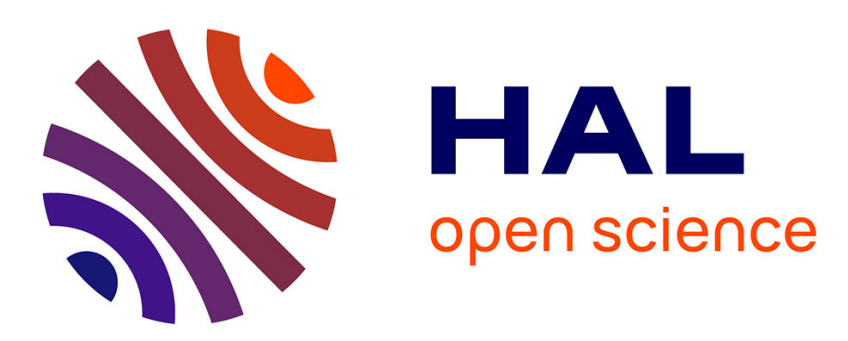

\title{
Thermodiffusion anisotropy under magnetic field in ionic liquid-based ferrofluids
}

\author{
T. Fiuza, M. Sarkar, J. C Riedl, A. Cēbers, F. Cousin, G. Demouchy, J. \\ Depeyrot, Dubois Emmanuelle, F. Gélébart, G. Mériguet, et al.
}

\section{To cite this version:}

T. Fiuza, M. Sarkar, J. C Riedl, A. Cēbers, F. Cousin, et al.. Thermodiffusion anisotropy under magnetic field in ionic liquid-based ferrofluids. Soft Matter, 2021, 17 (17), pp.4566-4577. 10.1039/d0sm02190c . hal-03219766

\section{HAL Id: hal-03219766 \\ https://hal.sorbonne-universite.fr/hal-03219766}

Submitted on 6 May 2021

HAL is a multi-disciplinary open access archive for the deposit and dissemination of scientific research documents, whether they are published or not. The documents may come from teaching and research institutions in France or abroad, or from public or private research centers.
L'archive ouverte pluridisciplinaire HAL, est destinée au dépôt et à la diffusion de documents scientifiques de niveau recherche, publiés ou non, émanant des établissements d'enseignement et de recherche français ou étrangers, des laboratoires publics ou privés. 


\title{
Journal Name
}

\section{ARTICLE TYPE}

Cite this: DOI: $00.0000 / \operatorname{xxxxxxxxxx}$

\section{Thermodiffusion anisotropy under magnetic field in ionic liquid-based ferrofluids}

\author{
T. Fiuza, ${ }^{a, b}$ M. Sarkar, ${ }^{a}$ J.C. Riedl,${ }^{a}$ A. Cēbers,${ }^{c}$ F. Cousin,${ }^{d}$ G. Demouchy,${ }^{a, e}$ \\ J. Depeyrot ${ }^{b}$ E. Dubois, ${ }^{a}$ F. Gélébart, ${ }^{a}$ G. Mériguet,${ }^{a}$ R. Perzynski, ${ }^{a}, *$ and V. Peyre ${ }^{a}$
}

Received Date

Accepted Date

DOI: $00.0000 / x x x x x x x x x x$
Ferrofluids based on maghemite nanoparticles (NPs), typically $10 \mathrm{~nm}$ in diameter, are dispersed in an ionic liquid (1-ethyl 3-methylimidazolium bistriflimide - EMIM-TFSI). The average interparticle interaction is found repulsive by small angle scattering of $X$-rays and of neutrons, with a second virial coefficient $A_{2}=7.3$. A moderately concentrated sample at $\Phi=5.95 \mathrm{vol} \%$ is probed by forced Rayleigh scattering under an applied magnetic field (up to $H=100 \mathrm{kA} \mathrm{m}^{-1}$ ) from room temperature up to $T=460 \mathrm{~K}$. Whatever $H$ and $T$, the NPs are here always found to migrate towards cold. The in-field anisotropy of the mass diffusion coefficient $D_{\mathrm{m}}$ and that of the (always positive) Soret coefficient $S_{\mathrm{T}}$ are well described by the presented model in the whole range of $H$ and $T$. The main origin of the anisotropy is the spatial inhomogeneities of concentration in the ferrofluid along the direction of applied field. Since this effect originates from the magnetic dipolar interparticle interaction, the anisotropy of thermodiffusion progressively vanishes when temperature increases and thermal motion rises.

\section{Introduction}

Ferrofluids ${ }^{1-4}$ based on Ionic Liquids (FF-ILs) are new colloidal dispersions of magnetic nanoparticles, developed for improving thermoelectric (TE) low-grade energy harvesting. Low-grade heat recovery is a very active field ${ }^{5,6}$ and the thermopower that can be extracted is largely discussed in topical papers ${ }^{7,8}$. Numerous recent works have been devoted to thermocells and thermionic capacitors of various kinds, using either polymer-based electrolytes ${ }^{9-11}$, crystallization of salt solutions ${ }^{12}$, small mobile ions in gels and solid matrices ${ }^{13,14}$, Ionic Liquids ${ }^{15,16}$ or colloidal charged nanoparticles in a standard electrolyte ${ }^{17-19}$. In classical ionic ferrofluids based on polar solvents, it has been recently shown that the application of a magnetic field is able to improve the thermoelectric properties of the material ${ }^{20}$. The use here of an Ionic Liquid (IL) as solvent brings new properties, among which the access to a wider range of temperatures $T^{21}$. In ionic liquids, which are molten salts at low $T$ 's only composed of anions and cations, the colloidal dispersions of nanoparticles (NPs) has been shown to be possible despite the totally different internal

\footnotetext{
${ }^{a}$ Sorbonne Université, CNRS, Lab. PHENIX, 4 Place Jussieu, F-75005 Paris, France.

${ }^{b}$ Grupo de Fluidos Complexos, Inst. de Fisíca, Univ. de Brasília, Brasília (DF), Brazil.

${ }^{c}$ MMML Lab, Faculty of Physics and Mathematics, University of Latvia, Zellu-8, LV1002 Riga, Latvia.

${ }^{d}$ Lab. Léon Brillouin - UMR 12 CNRS-CEA CEA-Saclay, 91191 Gif-sur-Yvette, France.

e Dpt de physique, Univ. de Cergy Pontoise, 33 Bd du Port, 95011 Cergy-Pontoise, France.

* corresponding author, regine.perzynski@sorbonne-universite.fr
}

structure of ILs from that of molecular solvents. NPs either coated by polymers, ${ }^{22-27}$ or coated with shorter surfactant chains, or even bare charged NPs ${ }^{27-33}$ have been dispersed in ILs. Among the extreme variety of room temperature ionic liquids ${ }^{34-36}, 1$ Ethyl-3-methylimidazolium bistriflimide (EMIM-TFSI), which is a widely used IL in applications ${ }^{37-39}$, can be considered as an important model system, since it is not too viscous at room temperature and is stable in a large range of $T^{21,36,40,41}$. Hydroxylcoated maghemite NPs, synthesized in water (diameter $\sim 10 \mathrm{~nm}$ ) are modified in order to adapt the NP/ solvent interface, i.e. the charge and the nature of the counterions, both shown to be cru$\mathrm{cial}^{27,30,31}$. After a liquid-liquid transfer from water to the IL, stable dispersions are obtained, that can be concentrated up to $\sim 12$ vol\% in EMIM-TFSI ${ }^{27,42}$, these dispersions remaining stable (from both a chemical and a colloidal point of view) at least up to $473 \mathrm{~K}^{42}$.

The long-term under-field colloidal stability of a ferrofluid based on an Ionic Liquid could be challenged in presence of temperature gradients. Probing its under-field thermodiffusive properties, in terms of Soret coefficient $S_{\mathrm{T}}$ and diffusion coefficient $D_{\mathrm{m}}{ }^{43}$, the more so at high temperatures, would be impossible if the colloid becomes unstable while submitted to $T$-gradients. Our aim is here to determine the under-field anisotropy of the NP's thermodiffusive properties at various mean temperatures, in a monophasic fluid phase, without any boundary such as the electrodes present in TE devices, which seriously modify the observed thermodiffusive properties ${ }^{19,44}$ and without the added re- 
dox couple which would be necessary for TE measurements. A forced Rayleigh scattering experiment ${ }^{45-52}$ is undertaken, in the presence of an applied magnetic field and in a wide range of mean temperatures $T$ (from room temperature up to $\sim 460 \mathrm{~K}$ ), using a moderately concentrated dispersion ( $\Phi=5.95$ vol\%) in order to render easier the under-field anisotropy measurement. As in ${ }^{53}$ for aqueous ferrofluids at room temperature, the results are here analysed according to the model developed in ${ }^{54}$ for stable colloidal dispersions. To perform these adjustments, it is of paramount importance to probe independently the interparticle interaction in the dispersion. This is undertaken here (under uniform $T$ ) for the first time in ferrofluids based on EMIM-TFSI by Small Angle Neutron Scattering (SANS) and Small Angle X-ray Scattering (SAXS) to determine the osmotic compressibility $\chi$ of the NP's system and the corresponding second Virial coefficient in the colloidal dispersion ${ }^{33,55}$.

In the next section we present the colloidal system, briefly recalling how it is prepared and the proposed origin of its stability, together with the probing by SAXS and SANS measurements of the interparticle repulsion in zero magnetic field. The third section is devoted to the forced Rayleigh scattering experiments and the obtained results in zero field and under applied field. The fourth section recalls the theoretical model used here to interpret the under-field measurements and its nice adjustment to the experimental data, which is besides demonstrating the under-field colloidal stability of the system in presence of temperature gradients. The last section presents a global discussion of the whole study .

\section{Magnetic Fluid samples}

\subsection{Synthesis}

The magnetic nanoparticles used here are chemically synthesized using a well-known aqueous coprecipitation method ${ }^{56,57}$. From the analysis of magnetic measurements (Vibrating Sample Magnetometer), their size distribution can be described by a log-normal distribution of median diameter $8.9 \mathrm{~nm}$ and a polydispersity index 0.23 , leading to a volume-averaged diameter $^{2} d_{\mathrm{NP}}=9.6 \mathrm{~nm}$. The details of the preparation of their dispersions in EMIM-TFSI are given extensively in ${ }^{27}$. Here is a short summary of the process. Firstly, the interface of the NPs is modified in water: a structural charge $Z \sim+400 \pm$ 100 is introduced. The species compensating their charge are deprotonated 1-(4-sulfobutyl)-3methylimidazolium bistriflimide $\left(\mathrm{SMIM}^{ \pm}-\mathrm{TFSI}^{-}\right)$, which has been shown to be close to the interface $^{27}$. Secondly, the ionic liquid is added and the water removed by freeze-drying, leading to NPs in pure EMIM-TFSI. All the process is performed with a volume fraction of NPs around $1 \%$.

EMIM-TFSI is a room-temperature ionic liquid, here supplied by Solvionic, with a viscosity ranging from $4 \times 10^{-2} \mathrm{~Pa}$ s at $294 \mathrm{~K}$ down to $3 \times 10^{-3} \mathrm{~Pa} \mathrm{~s}$ at $460 \mathrm{~K}$ (following ${ }^{36}$ ). It presents a low vapor pressure, a low flammability, a high ionic conductivity and a wide electro-chemical window $21,36,41$. It is also chemically stable up to high temperature (long-term $\sim 500 \mathrm{~K}$ and up to $\sim 700 \mathrm{~K}$ for shorter times ${ }^{21}$ ), making it a good candidate for thermoelectrical applications ${ }^{58}$. The colloidal dispersions of the used maghemite
NPs have been reported as being stable at room temperature in ${ }^{27}$ with a repulsive interparticle interaction.

A series of samples at various volume fractions $\Phi$ have been produced by ultracentrifugation of the initial dispersion at $\Phi \sim$ $1 \%$, following the method described in ${ }^{42}$.

\subsection{Colloidal stability - Interparticle interaction}

Small Angle X-ray Scattering (SAXS) experiments were carried out with the XEUSS 2.0 (Xenocs) of LLB-Saclay at room temperature on dispersions at several volume fractions $\Phi$ 's between $0.2 \%$ and $12 \%$. Complementary Small Angle Neutron Scattering (SANS) experiments were performed at PAXY spectrometer in Orphée - LLB - Saclay at various T's ranging between $293 \mathrm{~K}$ and $473 \mathrm{~K}$. All these experiments were performed without applied magnetic field. The scattered intensity $I(q)$, analyzed as in ${ }^{59,60}$, shows that the interparticle interaction is repulsive indeed. The determination of the intensity at low scattering vector $(q \rightarrow 0)$ leads to the osmotic compressibility $\chi$ of the NP's system, which is related to the osmotic pressure $\Pi$ of the NP's system by the following relation:

$$
\chi=\frac{k T}{\left(\frac{\partial \Pi v_{\mathrm{NP}}}{\partial \Phi}\right)_{T}},
$$

where $v_{\mathrm{NP}}$ is the NP's volume. The experimental results at room temperature and zero magnetic field are shown in Fig. 1. Moreover it has been observed that $\chi$ does not present any significant temperature dependence in the experimental $T$-range. As shown by Fig. 1 , the $\Phi$-dependence of $\chi$ can be described by the Carnahan-Starling formalism ${ }^{55,61}$ with effective hard spheres of volume fraction $\Phi_{\text {eff }}=1.82 \Phi$ and a second virial coefficient $A_{2}=7.3$.

The colloidal stability of the samples under-field up to $H=$ $716 \mathrm{kA} \mathrm{m}^{-1}$ (=9000 Oe) has been checked optically, looking at the scattering pattern of a non-absorbing laser beam, as described in 27,62 .

The colloidal stability of these samples, both in zero field and under-field, proves that a strong interparticle repulsion exists, which dominates the two kinds of interparticle attractions that are present here, van der Waals attraction (which is isotropic and is present in any colloid) and magnetic dipolar interaction specific of magnetic colloids such as those studied in the present work; They are anisotropic and attractive on average.

It has been proven both experimentally ${ }^{63-65}$ and by numerical simulations ${ }^{66-70}$ that along a flat and charged interface, Ionic Liquids can organize themselves as layers of ions, of alternating sign. Along a curved interface such as that of the present charged NPs ${ }^{32,71}$, long-range charge-density oscillations can be also formed, for given geometrical and charged conditions of the IL anions and cations $27,69,72$. If the number of organized layers is large enough, they are able to overcome attractive component of the interparticle interaction (usually van der Waals attraction) and stable colloidal dispersions can be obtained $27,30,32,72$. The colloidal stability of the present NPs in EMIM-TFSI is thus 


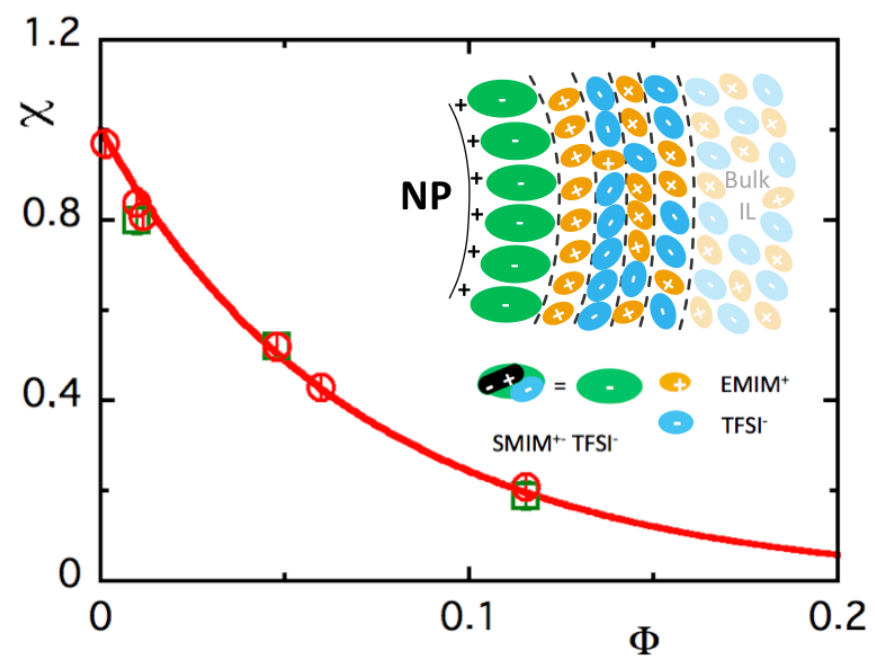

Fig. 1 Main figure: Osmotic compressibility $\chi$ of the NPs in the colloidal dispersions as a function of their volume fraction $\Phi$ - Open symbols: Experimental determinations at room temperature by SAXS (open circles) and SANS (open squares) - Full line: Carnahan-Starling adjustment with effective hard spheres ${ }^{55,61}$ of volume fraction $\Phi_{\text {eff }}=1.82 \Phi$ leading to $A_{2}=7.3$; Inset: Sketch of the ionic layering around the NPs responsible for the colloidal stability of the dispersion. The NP's surface, which is positive due to the hydroxyls groups, is compensated by a first layer of condensed $\mathrm{SMIM}^{ \pm}-\mathrm{TFSI}^{-}$counterions, layer which initiates the long range IL-layering.

proposed to come here from the "effective" interparticle repulsion, due to the regular layering of ions, of alternate sign, around the NPs (see the sketch in the inset of Fig. 1), which dominates both van der Waals and magnetic dipolar interparticle attractions. Here the resultant characteristic length $\kappa^{-1}$ of repulsive (on average) interparticle interaction ${ }^{73}$ can be extracted from the Carnahan-Starling adjustment of $\chi(\Phi)$, writing ${ }^{33} \Phi_{\text {eff }} / \Phi$ as $\left[\left(d_{\mathrm{NP}}+2 \kappa^{-1}\right) / d_{\mathrm{NP}}\right]^{3}$. It leads to $\kappa^{-1} \sim 1.1 \mathrm{~nm}$. The structure of the liquid being modified on few $\kappa^{-1}$, typically up to $5 \kappa^{-1}$, it corresponds to 6-7 layers of anions and cations from the $\mathrm{IL}^{31}$.

\section{Forced Rayleigh scattering experiment}

\subsection{Experimental device}

The setup we use for these forced Rayleigh scattering* (FRS) measurements (see Fig. 2) has been initially presented in ref. ${ }^{49}$. A high power lamp (Oriel 6285 - $500 \mathrm{~W}$ - Hg Arc Lamp) illuminates a grid, the image of which is made in the liquid sample, put in a thin and thermalized optical cell (of thickness $e=25 \mu \mathrm{m}$ ). Because of the strong optical absorption of the maghemite NPs, a thermal grating of time-dependent amplitude $\Delta T(t)$ and of spatial period $\Lambda$ ranging between 88 and $145 \mu \mathrm{m}$ is created in the NP dispersion. A concentration grating of amplitude $\Delta \Phi(t)$ with the same spatial period $\Lambda$ is then induced thanks to the LudwigSoret effect ${ }^{74,75}$. Both the thermal and the concentration gratings

* Forced Rayleigh scattering implies forced inhomogeneities ${ }^{45}$.
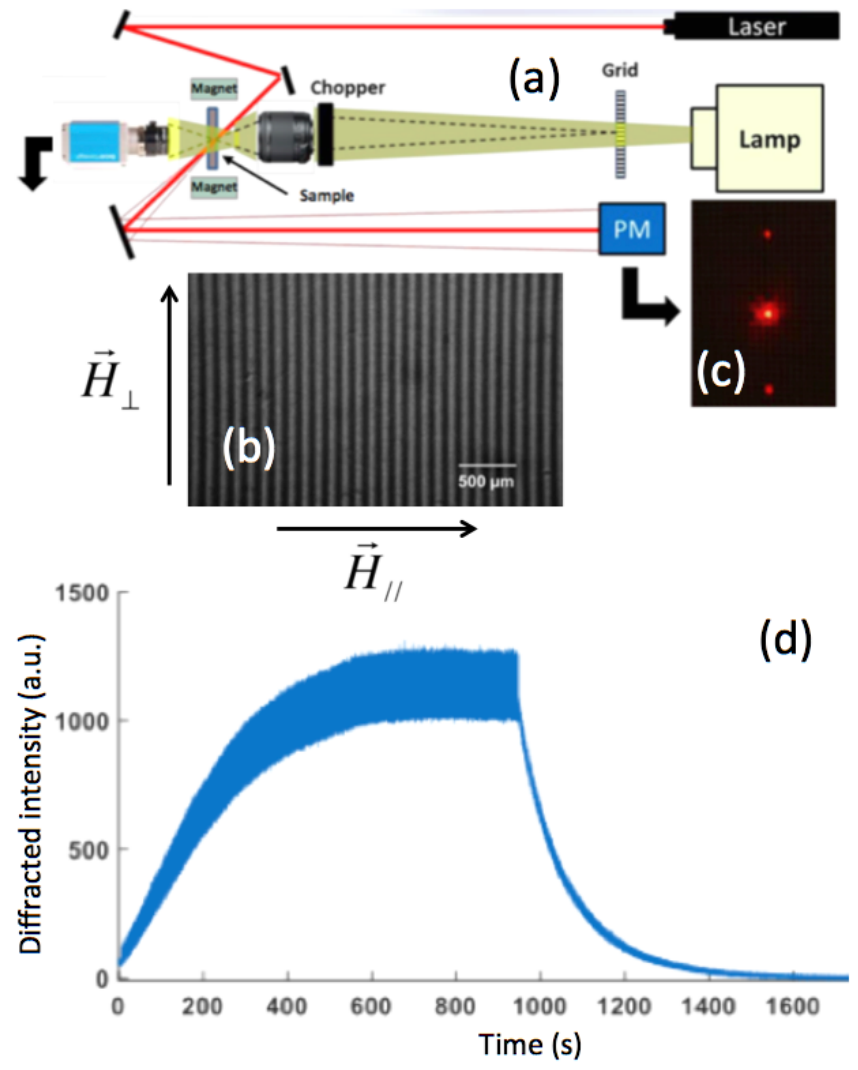

Fig. 2 Forced Rayleigh scattering device: (a) Experimental set-up, seen from above; The Hg-lamp illuminates a grid, the image of which is made, periodically at a few $\mathrm{Hz}$, in the thermalized sample, possibly submitted to an horizontal magnetic field $\vec{H}$; Both a thermal and a concentration arrays are induced in the sample (for more details see text); Their temporal evolution is observed by the diffraction of a He-Ne laser beam; (b) Direct observation of the image of the grid in the sample; The applied field is either parallel $\left(\vec{H}_{\|}\right)$to the horizontal thermal gradients or perpendicular $\left(\vec{H}_{\perp}\right)$ to the vertical thermal gradients; (c) Diffracted pattern of the He-Ne laser beam by the temperature and concentration arrays; (d) Recorded intensity of the first order diffraction at $\Phi=5.95 \%$ as a function of time; When the heating beam is cut, the recorded intensity relaxes towards zero.

are here probed with the first order diffraction of a He-Ne laser beam, which is poorly absorbed by these dispersions. The Soret coefficient $S_{\mathrm{T}}$ links the applied temperature gradient $\vec{\nabla} T$ and the induced volume-fraction gradient $\vec{\nabla} \Phi$, in the following way:

$$
\vec{\nabla} \Phi=-\Phi S_{\mathrm{T}} \vec{\nabla} T
$$

$S_{\mathrm{T}}$ is obtained here by means of a modulation at $4 \mathrm{~Hz}$ of the $\mathrm{Hg}$ lamp intensity (the thermal response of the system being by orders of magnitude faster than the concentration one) and thanks to the knowledge of $\partial n / \partial T$ and $\partial n / \partial \Phi^{\dagger}$ (for details see ${ }^{52}$ and its

$\dagger$ The derivative $\partial n / \partial T$ is taken equal to $-2.82 \times 10^{-4} \mathrm{~K}^{-1}$ following Kamysbayev et $\mathrm{al}^{72}$, independent of $T$ in our range of $T$ from the optical index measurement of Seki et $\mathrm{al}^{76}$ (even if only measured up to $353 \mathrm{~K}$ ); The derivative $\partial n / \partial \Phi$ is taken equal to 
E.S.I..). If $\Delta \Phi_{\mathrm{St}}$ is the spatial modulation of volume fraction in stationary conditions, we obtain:

$$
S_{\mathrm{T}}=-\frac{\Delta \Phi_{\mathrm{St}}}{\Phi\langle\Delta T\rangle}
$$

$\Delta \Phi_{\mathrm{St}}$ being negative with the convention of ${ }^{52}$ and $\langle\Delta T\rangle$ being the time-averaged spatial modulation of temperature. As an example, at $\Phi=5.95 \%$, we obtain here $\left|\Delta \Phi_{\mathrm{St}}\right| / \Phi \leq 10^{-2}$ and $\langle\Delta T\rangle \leq 0.1 \mathrm{~K}$ whatever the amplitude and the direction of the applied field $\vec{H}$ and whatever $T$ in the experimental range.

Switching off the Hg lamp makes the concentration grating relax as well as the modulation of the optical index related to $\Delta \Phi(t)$ and thus also the intensity of the diffracted beam (see Fig. 2(d)), allowing a determination of the mass diffusion coefficient $D_{\mathrm{m}}$ of the NPs.

$$
\Delta \Phi(t)=\Delta \Phi_{\mathrm{St}} \mathrm{e}^{-q^{2} D_{\mathrm{m}} t}
$$

with $q=2 \pi / \Lambda$.

The sample environment is thermo-regulated (here temperature $T$ may vary from room temperature up to $460 \mathrm{~K}$ ). It is also possible to apply an horizontal magnetic field $\vec{H}$, homogeneous at the scale of the sample, thanks to movable magnetic polar pieces (here $H$ may vary from 0 up to $100 \mathrm{kA} \mathrm{m}^{-1}$ ), making possible to determine both $S_{\mathrm{T}}(H, T)$ and $D_{\mathrm{m}}(H, T)$ in a large range of temperature and magnetic field. The under-field anisotropy of $S_{\mathrm{T}}(H, T)$ and $D_{\mathrm{m}}(H, T)$ is probed by orienting the temperature gradient (and thus also the concentration gradient) either horizontally or vertically, optical cell and grating being both in the vertical plane. All problems of gravity such as convection and instabilities do not occur here because of the small values of $\Delta \Phi$ and of the sample thickness. In-field measurements are performed at ratios sample thickness $e$ over spatial period $\Lambda$, such that $0.17<e / \Lambda<0.28$, thus in the 2D-array conditions. The experiments are also performed at magnetic fields $\vec{H}$ below the threshold of 2D magnetoconvection $^{78,79}$.

It is checked that the measured $S_{\mathrm{T}}$ is independent of $\Lambda$ and of the power of the $\mathrm{Hg}$ lamp (the experimental range is limited to the power linear regime ${ }^{80}$ ).

\subsection{Experimental results in zero field}

Fig. 3 presents the values of $D_{\mathrm{m}}$ (main figure) and $S_{\mathrm{T}}$ (inset) obtained experimentally in zero magnetic field at various temperatures $T$ and volume fractions $\Phi$.

\subsubsection{Diffusion coefficient in zero field}

In zero applied magnetic field, the mass diffusion coefficient $D_{\mathrm{m}}$ is isotropic and equals:

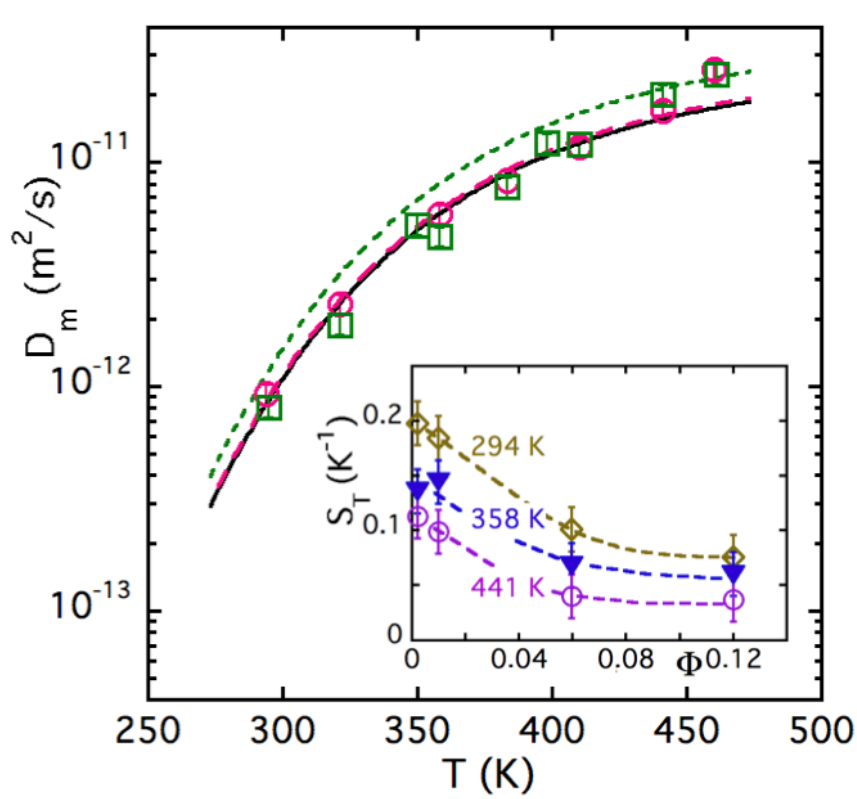

Fig. 3 Main figure: Diffusion coefficient $D_{\mathrm{m}}$ at various $\Phi$ as a function of $T$. The symbols are experimental determinations at $5.95 \%$ (open squares) and $\Phi=1 \%$ (open circles). The full line corresponds to the ideal case $D_{\mathrm{m}}(\Phi \rightarrow 0, T)$ given by Eq. 7 . The dashed lines correspond to the general case of Eq. 5 taking into account the interparticle correlations with $\chi=0.86$ at $\Phi=1 \%$ (pink dashed line) and 0.43 at $\Phi=5.95 \%$ (green dashed line), $\zeta(\Phi, T)$ being given by Eq. 8 with the hard sphere volume fraction equal to $\Phi_{\text {eff }}=1.82 \Phi$. Inset: Soret coefficient $S_{\mathrm{T}}$ at various $T$ 's as a function of $\Phi$. Dashed lines are guide for the eye.

$$
D_{\mathrm{m}}(\Phi, T)=\frac{1}{\zeta} \frac{\partial \Pi v_{\mathrm{NP}}}{\partial \Phi}=\frac{1}{\zeta(\Phi, T)} \frac{k T}{\chi(\Phi)}
$$

where the compressibility $\chi(\Phi)$ is given by Eq. 1 and Fig. $1 ; \chi$ has been shown experimentally to be $T$-independent. Oppositely the friction term $\zeta$ is $\Phi$ and $T$-dependent.

In the absence of interparticle correlations $(\Phi \rightarrow 0), \chi=1$ and the friction $\zeta(T)$ writes as:

$$
\zeta(\Phi \rightarrow 0, T)=\zeta_{0}(T)=3 \pi \eta_{0}(T) d_{\mathrm{H}}
$$

where $\eta_{0}(T)$ is the solvent viscosity and $d_{\mathrm{H}}$ the NP's hydrodynamic diameter. The mass diffusion coefficient $D_{\mathrm{m}}(\Phi \rightarrow 0, T)$ can then be written as :

$$
D_{\mathrm{m}}(\Phi \rightarrow 0, T)=\frac{k T}{\zeta_{0}(T)}=\frac{k T}{3 \pi \eta_{0}(T) d_{\mathrm{H}}}
$$

In the presence of interparticle correlations $\chi \neq 1$ and $\zeta(T) \neq$ $\zeta_{0}(T)$, these correlations modify $D_{\mathrm{m}}$. An expression for the friction experienced by hard spheres in hydrodynamic interaction at a volume fraction $\Phi$ has been proposed in ${ }^{81}$ for $\Phi \ll 1$ :

$$
\zeta(\Phi, T)=\zeta_{0}(T)\left(1+k_{\mathrm{F}} \Phi\right) \quad \text { with } \quad k_{\mathrm{F}}=6.55
$$


The evolution of $D_{\mathrm{m}}(\Phi, T)$ as a function of $T$ is plotted in main Fig. 3. The full line is the computation of $D_{\mathrm{m}}(\Phi \rightarrow 0, T)$ as a function of $T$ taking $\eta_{0}(T)$ as given by ${ }^{36}$ and $d_{\mathrm{H}}=13.6 \mathrm{~nm}$. As shown by this figure and Eq. 7, the strong temperature dependence of $D_{\mathrm{m}}(\Phi \rightarrow 0, T)$ can be ascribed to the large decrease of the solvent viscosity $\eta_{0}(T)$ as $T$ increases.

However, note that here, the NPs present strong interparticle repulsion (as shown by Fig. $1, \chi=0.43$ at $\Phi=5.95 \%$ ). These interparticle correlations cannot be forgotten in the expression of $D_{\mathrm{m}}(\Phi, T)$. Fig. 3 thus also presents $D_{\mathrm{m}}(\Phi, T)$ as obtained from the general expression of Eq. 5 for $\Phi=5.95 \%$ (dashed line) and $\Phi=1 \%$ (long dashed line), using SAXS and SANS experimental $\chi$ values and Eq. 8 with $\Phi_{\text {eff }}(=1.82 \Phi)$ as hard sphere volume fraction. It matches correctly the experimental results at $\Phi=1 \%$, which are close to the ideal case $D_{\mathrm{m}}(\Phi \rightarrow 0, T)$ due to a compensation between $\chi(\Phi=1 \%)$ and $\zeta(T, \Phi=1 \%) / \zeta_{0}(T)$ - except at $T \geq 420 \mathrm{~K}$, but it should be necessary to check that the viscosity values deduced from the calculations of Paduszynski and Domanska $^{36}$ are completely reliable in this range of $T$. On the contrary, a systematic discrepancy (by a factor ranging from 1.4 at room temperature down to 1.2 at $420 \mathrm{~K}$ ) is found at $\Phi=5.95 \%$, meaning that the friction $\zeta$ is $40 \%$ to $20 \%$ larger than what is given by the development of Eq. 8 at this volume fraction in this temperaturerange.

\subsubsection{Soret coefficient in zero field}

Inset of Fig. 3 shows the evolution of the Soret coefficient $S_{\mathrm{T}}$ as a function of the volume fraction $\Phi$ at three different temperatures. Let us note first that whatever $\Phi$ and $T$, the measured $S_{\mathrm{T}}$ is here always positive, contrary to what is sometimes observed for ferrofluids in water 48,53 and similarly to what is observed with ferrofluids in another very different ionic liquid (ethylammonium nitrate, EAN) ${ }^{33}$. EAN is indeed hydrophilic and totally miscible with water, whereas EMIM-TFSI is hydrophobic ${ }^{\ddagger}$.

Moreover the Soret coefficient $S_{\mathrm{T}}$ is a decreasing function of $\Phi$, which is expected as it has been shown in 43,55 that

$$
\left|S_{\mathrm{T}}\right| \propto \chi
$$

which is here a decreasing function of $\Phi-$ see Fig. $1 . S_{\mathrm{T}}$ also decreases as a function of $T$, as observed in EAN $^{33}$. For a deeper analysis of the behaviour of $S_{\mathrm{T}}(\Phi, T)$ (as in ${ }^{33}$ for example), a larger number of samples at various volume fractions $\Phi$ should be investigated. It will be done in a forthcoming paper, we focus hereafter on the under-field behavior of only one sample $(\Phi=$ $5.95 \%$ ) in the whole accessible $T$-range of the experiment.

\subsection{Under-field experimental results}

An anisotropy of both the diffusion coefficient $D_{\mathrm{m}}$ (see Fig. 4) and of the Soret coefficient $S_{\mathrm{T}}$ (see Fig. 5) is observed whatever $T$ ranging between $295 \mathrm{~K}$ and $460 \mathrm{~K}$, if an external magnetic field $\vec{H}$ is applied to the sample during the FRS measurement $(0 \leq$ $H \leq 100 \mathrm{kA} \mathrm{m}^{-1}$ ). $D_{\mathrm{m}}$ and $S_{\mathrm{T}}$ both depend on the amplitude of

$\ddagger$ Note that the NP/ liquid interface is not constituted of the same species and H-bonds can occur with EAN while only weaker ones can exist with EMIM-TFSI. the applied field and on its direction, as it has been previously observed for $D_{\mathrm{m}}$ and/or $S_{\mathrm{T}}$ in non-ionic magnetic fluids ${ }^{82-84}$ and in aqueous ferrofluids $46,53,85,86$ at room temperature.

We recall that we limit ourselves here to gradients of temperature $(\vec{\nabla} T)$ and of concentration $(\vec{\nabla} \Phi)$ either horizontal (and thus parallel $(\|)$ to the applied field - this direction is here denoted $\vec{H}_{\|}$) or vertical (and thus perpendicular $(\perp)$ to the field - this direction is here denoted $\vec{H}_{\perp}$ ) .

Fig. 4 and 5 show typical in-field anisotropies of $D_{\mathrm{m}}$ and of $S_{\mathrm{T}}$ observed at $\Phi=5.95 \%$ and $0 \leq H \leq 100 \mathrm{kA} \mathrm{m}^{-1}$, for both $\vec{H}_{\|}$and $\vec{H}_{\perp}$. As previously shown in main Fig. 3, the zero field value of $D_{\mathrm{m}}$ increases with $T$. Under-field $D_{\mathrm{m}}$ is anisotropic with $D_{\mathrm{m}}\left(H_{\perp}\right)<D_{\mathrm{m}}(H=0)<D_{\mathrm{m}}\left(H_{\|}\right)$and this anisotropy decreases with $T$. In an opposite manner (as also previously shown in inset of Fig. 3), the zero field value of $S_{\mathrm{T}}$ decreases with $T$ with an underfield anisotropy of $S_{\mathrm{T}}$, with $S_{\mathrm{T}}\left(H_{\|}\right)<S_{\mathrm{T}}(H=0)<S_{\mathrm{T}}\left(H_{\perp}\right)$. Let us note that, in the experimental range, whatever the amplitude of $\vec{H}$ and whatever its direction with respect to $\vec{\nabla} \Phi$ and $\vec{\nabla} T, S_{\mathrm{T}}(H)$ remains always positive, as $S_{\mathrm{T}}(H=0)$.

\section{Under-field model and adjustment of the experimental results}

\subsection{Under-field model of diffusion coefficient}

At room temperature, the in-field anisotropy of $D_{\mathrm{m}}$ in aqueous samples, measured in the absence of temperature gradient, has been extensively described with a mean-field framework in $46,85,86$. In this framework, the effective Langevin parameter $\xi_{e}$ in the ferrofluid, based on NPs of magnetization $m_{\mathrm{S}}$ with a volume $v_{\mathrm{NP}}$ and a magnetic moment $\mu_{\mathrm{NP}}=m_{\mathrm{S}} v_{\mathrm{NP}}$, is defined as :

$$
\xi_{e}=\xi(H, T)+\lambda \gamma L\left(\xi_{e}\right) \quad \text { with } \quad \xi(H, T)=\frac{\mu_{0} \mu_{\mathrm{NP}} H}{k T}
$$

$\xi(H, T)$ is the Langevin parameter, $\lambda$ the mean-field parameter, $\gamma$ the magnetic dipolar interaction parameter

$$
\gamma(\Phi, T)=\frac{\mu_{0} m_{\mathrm{S}} \mu_{\mathrm{NP}} \Phi}{k T}
$$

and $L(\xi)=\operatorname{cotan}(\xi)-1 / \xi$ the Langevin function. Here we use $\lambda=0.22$ as in $46,85,87$, value confirmed by the numerical simulations in water of ref. ${ }^{86} \S$. Under-field, the chemical potential of the dispersion then contains a supplementary additive term $\mu_{\mathrm{H}} 3,85,92$ :

$$
\mu_{\mathrm{H}}=-k T \ln \frac{\operatorname{sh} \xi_{e}}{\xi_{e}}
$$

The in-field diffusion coefficient $D_{\mathrm{m}}$ writes with $\vec{\nabla} T\|\vec{\nabla} \Phi\| \vec{O} y$, either perpendicular to the applied field $\vec{H}\left(\vec{H}_{\perp}\right)$ or parallel

$\S$ The validity of the simple mean-field model of Eq. 10 with $\lambda=0.22$ has been tested up to $\gamma \sim 5$. It has been shown (at room temperature) in ref. ${ }^{88,89}$ that this model gives same initial magnetic susceptibility as the second order perturbation model of Ivanov and Kuznetsova ${ }^{90}$ with $\lambda=1 / 3$ and as the mean-spherical model of Morozov and Lebedev ${ }^{91}$, all the three being in good agreement with experiments. 
$\left(\vec{H}_{\|}\right)^{3,85}$ (see inset b in Fig. 2):

$$
D_{\mathrm{m}}^{\overrightarrow{H_{\perp}}}=\frac{k T}{\zeta}\left(\frac{1}{\chi}-\alpha_{\lambda}\right)=D_{\mathrm{m}}^{*}\left[1-\chi \alpha_{\lambda}\right]
$$

and

$$
D_{\mathrm{m}}^{\vec{H}_{\|}}=\frac{k T}{\zeta}\left(\frac{1}{\chi}+\beta_{\lambda}-\alpha_{\lambda}\right)=D_{\mathrm{m}}^{*}\left[1+\chi\left(\beta_{\lambda}-\alpha_{\lambda}\right)\right]
$$

where $D_{\mathrm{m}}^{*}(\Phi, T)=D_{\mathrm{m}}(H \rightarrow 0, \Phi, T)$, the parameters $\alpha_{\lambda}$ and $\beta_{\lambda}$ being given by ${ }^{3,85}$ :

$$
\alpha_{\lambda}=-\frac{\Phi}{k T}\left(\frac{\partial \mu_{\mathrm{H}}}{\partial \Phi}\right)_{\mathrm{H}}=\frac{\lambda \gamma L^{2}\left(\xi_{e}\right)}{1-\lambda \gamma L^{\prime}\left(\xi_{e}\right)}
$$

and

$$
\beta_{\lambda}=\frac{\Phi}{k T \partial \Phi / \partial y}\left(\frac{\partial \mu_{\mathrm{H}}}{\partial \mathrm{H}}\right)_{\Phi}=\frac{\gamma L^{2}\left(\xi_{e}\right)}{\left[1-\lambda \gamma L^{\prime}\left(\xi_{e}\right)\right]\left[1+(1-\lambda) \gamma L^{\prime}\left(\xi_{e}\right)\right]} .
$$

$\alpha_{\lambda}$ is associated with the mean-field-averaged dipolar interaction, which is here isotropic and attractive. The term $\beta_{\lambda}$ is anisotropic and due to the discontinuity of $\vec{H}_{\|}$in Maxwell equations along the spatial inhomogeneities of concentration ${ }^{\text {II }}$ over the $\mathrm{y}$ axis $3,46,54,85$. $\beta_{\lambda}$ is maximum in the field direction parallel to $\vec{\nabla} \Phi$ and null perpendicularly. The higher is the volume fraction $\Phi$, the larger are magnetic dipolar parameter $\gamma$ and coefficient $\beta_{\lambda}$, and thus the larger is the anisotropy of $D_{\mathrm{m}}$.

The adjustments of $D_{\mathrm{m}}^{\vec{H}_{\perp}}$ and $D_{\mathrm{m}}^{\vec{H}_{\|}}$at room temperature are both presented in Fig. 4. They are made, assuming as in refs. ${ }^{46,85,87}$ that $\chi$ and $\zeta$ keep under-field their zero field value. Using $\chi=0.43$ and $m_{\mathrm{S}}=3.2 \times 10^{5} \mathrm{~A} \mathrm{~m}^{-1}$, and letting in the fit $d_{\mathrm{NP}}$ and $D_{\mathrm{m}}^{*}$ as free parameters. $D_{\mathrm{m}}^{*}$ is found within the experimental error bar of $D_{\mathrm{m}}(H=0)$ and we obtain $d_{\mathrm{NP}}=13.2 \mathrm{~nm}$, leading to $\gamma=2.3$ at room temperature. In the monodisperse model used here for the adjustment, the polydispersity in NP's diameter is not taken in account and the value of $d_{\mathrm{NP}}$ obtained is $30 \%$ larger than the volume average diameter obtained from magnetization measurements. It is anyway reasonable as it corresponds to a reduced dipolar parameter $\Psi_{\mathrm{dd}}=\gamma / \Phi=39$, quite comparable to those previously obtained experimentally for aqueous samples based on maghemite NPs similar in diameter ${ }^{88,89}$.

At higher temperatures than $295 \mathrm{~K}$, the osmotic compressibility $\chi$, as determined by SANS measurements at $H=0$, is observed to be independent of $T^{42}$. The temperature dependence of $\zeta(T)$ enters inside the fitting parameter $D_{\mathrm{m}}^{*}(T)$, still kept within the experimental error bar of $D_{\mathrm{m}}(H=0)$ at the given $T$.

However two other parameters have to be modified in the model because of their $T$-dependence and that of the NP's magnetization $m_{\mathrm{S}}(T)$. Namely these two parameters are the Langevin parameter

$$
\xi(H, T) \propto \frac{\mu_{\mathrm{NP}}}{T} \propto \frac{m_{\mathrm{S}}(T)}{T}
$$

II Such under-field inhomogeneities of concentration are also present at the local scale as attested by small angle scattering ${ }^{87,93}$.

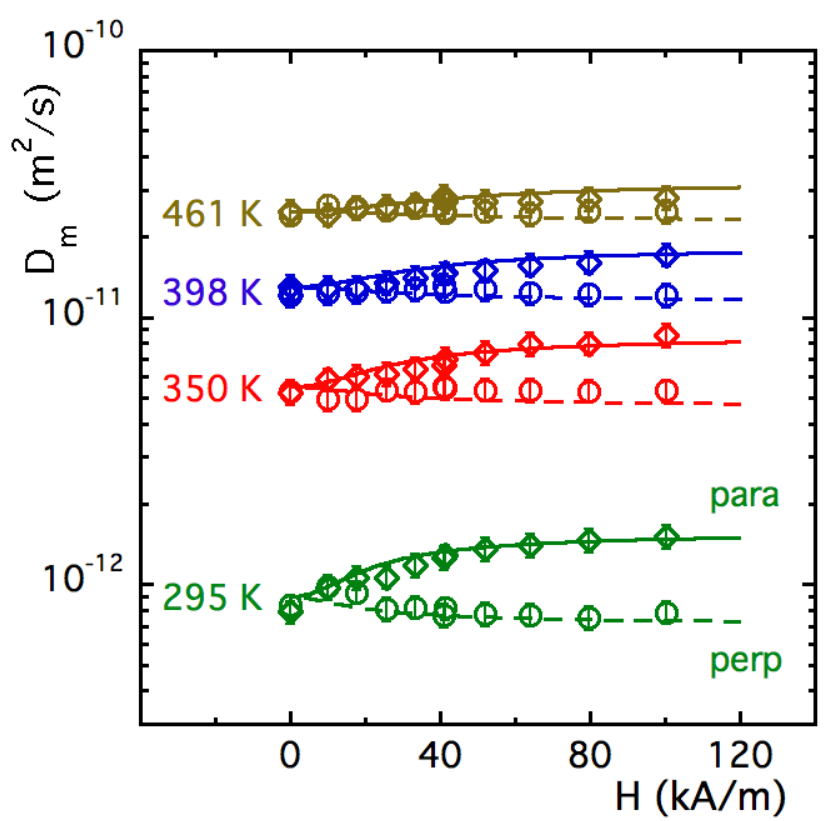

Fig. 4 Under-field diffusion coefficient $D_{\mathrm{m}}$ as a function of the applied field for different temperatures $T$ (from bottom to top: 295, 350, 398 and $461 \mathrm{~K}$ ); The label perp (resp. para) and open discs (resp. open diamonds) mean measurements in $H_{\perp}$ direction (resp. $H_{\|}$); Symbols correspond to FRS measurements, dashed lines (resp. full lines) correspond to adjustment of the data in $H_{\perp}$ direction with Eq. 13 (resp. in $H_{\|}$direction with Eq. 14). See the text for the detailed values of the parameters used.

and the dipolar parameter

$$
\gamma(\Phi, T) \propto \frac{m_{\mathrm{S}} \mu_{\mathrm{NP}}}{T} \propto \frac{m_{\mathrm{S}}^{2}(T)}{T}
$$

In a first approximation, it is here proposed to approximate the temperature dependence of $m_{\mathrm{S}}$ with the following Bloch law of bulk maghemite ${ }^{94-97}$ as finite-size effects and interface effects on the magnetization are small for the present size of NPs ${ }^{98-101}$ :

$$
m_{\mathrm{S}}(T)=390\left(1-3.3 \times 10^{-5} T^{\frac{3}{2}}\right),
$$

where $m_{\mathrm{S}}$ is expressed in $\mathrm{kA} \mathrm{m}^{-1}, T$ in K. Note that Eq. 19 is only valid up to $723 \mathrm{~K}$, temperature above which maghemite transforms in hematite ${ }^{94,95}$.

Fig. 4 presents the adjustment of the in-field anisotropy of $D_{\mathrm{m}}$ at $\Phi=5.95 \%$ and various $T$ 's, with $\chi$ kept independent of $\vec{H}$ and $T$ as said above, $d_{\mathrm{NP}}=13.2 \mathrm{~nm}$ and $D_{\mathrm{m}}^{*}$ being the only $T$-dependent fitting parameter. At each $T$, the shape of the anisotropy of $D_{\mathrm{m}}$ is well adjusted with the model of Eqs. 13, 14, 15 and 16 with a dipolar interaction parameter $\gamma(T)$ derived from Eqs. 11 and 19 given in Table 1 . The model quite nicely reproduces the anisotropy of $D_{\mathrm{m}}$ in the experimental range of $T$ and $\vec{H}$.

\subsection{Under-field model of Soret coefficient}

The in-field anisotropy of the Soret coefficient $S_{\mathrm{T}}(\vec{H})$ can be expressed in the same framework as that of Eqs. 13 and 14 for 
Table 1 Evolution of some parameters as a function of temperature $T: \gamma$ magnetic dipolar parameter deduced from Eq. 11 using $d_{\mathrm{NP}}=13.2 \mathrm{~nm}$ and Eq. 19; $D_{\mathrm{m}}(H=0)$ experimental value of diffusion coefficient $D_{\mathrm{m}}$ in zero magnetic field; $D_{\mathrm{m}}^{*}$ value of $D_{\mathrm{m}}$ in zero magnetic field deduced from the underfield adjustment of $D_{\mathrm{m}}(H) ; S_{\mathrm{T}}(H=0)$ experimental value of Soret coefficient $S_{\mathrm{T}}$ in zero magnetic field; $S_{\mathrm{T}}^{*}$ value of $S_{\mathrm{T}}$ in zero magnetic field deduced from the under-field adjustment of $S_{\mathrm{T}}(H)$.

\begin{tabular}{llllllll}
\hline$T(\mathrm{~K})$ & $\gamma$ & $D_{\mathrm{m}}(H=0)\left(\mathrm{m}^{2} / \mathrm{s}\right)$ & $D_{\mathrm{m}}^{*}\left(\mathrm{~m}^{2} / \mathrm{s}\right)$ & $\frac{D_{\mathrm{m}}^{*}-D_{\mathrm{m}}(H=0)}{D_{\mathrm{m}}^{*}}$ & & $S_{\mathrm{T}}(H=0)\left(\mathrm{K}^{-1}\right)$ & $S_{\mathrm{T}}^{*}\left(\mathrm{~K}^{-1}\right)$ \\
\hline 295 & 2.3 & $8.0610^{-13}$ & $9.010^{-13}$ & $+10 \%$ & 0.099 & 0.089 & $-11 \%$ \\
350 & 1.7 & $5.2410^{-12}$ & $5.710^{-12}$ & $+8 \%$ & 0.070 & 0.064 & $-9 \%$ \\
398 & 1.3 & $1.2110^{-11}$ & $1.310^{-11}$ & $+7 \%$ & 0.054 & 0.05 & $-8 \%$ \\
461 & 0.92 & $2.4510^{-11}$ & $2.510^{-11}$ & $+2 \%$ & 0.037 & 0.036 & $-3 \%$ \\
\hline
\end{tabular}

$D_{\mathrm{m}}(\vec{H})$ but including derivatives of the NP's chemical potential with respect to temperature ${ }^{53,54}$ :

$$
S_{\mathrm{T}}^{\vec{H}_{\perp}}=\frac{1}{1-\chi \alpha_{\lambda}}\left[S_{\mathrm{T}}^{*}+\chi \frac{S_{1}}{T}\right]
$$

and

$$
S_{\mathrm{T}}^{\vec{H}_{\|}}=\frac{1}{1+\chi\left(\beta_{\lambda}-\alpha_{\lambda}\right)}\left[S_{\mathrm{T}}^{*}+\chi \frac{S_{1}-S_{2}}{T}\right],
$$

where $S_{\mathrm{T}}^{*}=S_{\mathrm{T}}(H \rightarrow 0, \Phi, T)$, the parameters $S_{1}$ and $S_{2}$ being given by :

$$
S_{1}=\frac{\xi_{e} L\left(\xi_{e}\right)}{1-\lambda \gamma L^{\prime}\left(\xi_{e}\right)}-\ln \frac{\sinh \xi_{e}}{\xi_{e}}
$$

and

$$
S_{2}=\beta_{\lambda} \frac{\xi_{e} L^{\prime}\left(\xi_{e}\right)}{L\left(\xi_{e}\right)} .
$$

These equations involve the same parameters as Eqs. 13 and 14 , in particular $\xi_{e}$ (effective Langevin parameter given by Eq. 10), $\lambda$ (mean field parameter, here fixed to 0.22), $\gamma(T)$ (dipolar interaction parameter deduced from Eqs. 11 and 19), $\alpha_{\lambda}$ and $\beta_{\lambda}$ given by Eqs. 15 and 16. We use in Fig. 5 the same values of all these parameters as in Fig. 4 and only keep free $S_{\mathrm{T}}^{*}$ as a $T$ dependent parameter, adjusted within the experimental error bar of $S_{\mathrm{T}}(H=0)$ at the given temperature. A quite reasonable agreement with the experimental variation of in-field anisotropy of the Soret coefficient $S_{\mathrm{T}}(\vec{H})$ is obtained in the whole range of $T$ and $\vec{H}$.

$D_{\mathrm{m}}^{*}(T)$ and $S_{\mathrm{T}}^{*}(T)$, which have been left free because of the substantial experimental error bars on the direct experimental determinations of $D_{\mathrm{m}}$ and $S_{\mathrm{T}}$ in zero field at $T$, presents however a systematic small shift with respect to these values (see Table 1). This shift, which remains within the experimental error bar, is positive for $D_{\mathrm{m}}^{*}$ and negative for $S_{\mathrm{T}}^{*}$.

\section{Discussion}

Let us go deeper in the analysis of each of the terms entering in the adjustments, to try to separate their respective influences. In the under-field analysis the two main contributions to $D_{\mathrm{m}}(\vec{H})$ and $S_{\mathrm{T}}(\vec{H})$ come from the two parameters $\alpha_{\lambda}$ and $\beta_{\lambda}$, which equal zero at zero magnetic field. The term $\alpha_{\lambda}$ is related to the underfield dipolar interaction, modeled in the framework of a mean field approximation. It decreases as $T$ increases. In this framework, it is isotropic and thus exists in both directions $\vec{H}_{\perp}$ and $\vec{H}_{\|}$. In the model, the under-field anisotropic contribution to $D_{\mathrm{m}}(H)$ comes from the under-field inhomogeneities of concentra- tion, modeled by $\beta_{\lambda}$. This anisotropic term, which is also proportional to the magnetic dipolar parameter $\gamma(T)$, becomes weaker as $T$ increases. Let us first briefly have a deeper look on these two terms $\alpha_{\lambda}$ and $\beta_{\lambda}$, and on their influence on the under-field variations of $D_{\mathrm{m}}(\vec{H})$ and $S_{\mathrm{T}}(\vec{H})$. We then will focus on the two terms $S_{1}$ and $S_{2}$.

It is possible to compare the theoretical expressions of $\alpha_{\lambda}$ and $\beta_{\lambda}$ given by Eqs. 15 and 16 to direct experimental determinations, namely"l :

$$
-\alpha_{\lambda}=\frac{1}{\chi} \frac{D_{\mathrm{m}}^{\vec{H}_{\perp}}-D_{\mathrm{m}}^{*}}{D_{\mathrm{m}}^{*}}
$$

as in $\vec{H}_{\perp}$ direction $\alpha_{\lambda}$ solely appears in $D_{\mathrm{m}}$ and

$$
\beta_{\lambda}=\frac{1}{\chi} \frac{D_{\mathrm{m}}^{\vec{H}_{\mathrm{f}}}-D_{\mathrm{m}}^{\vec{H}_{\perp}}}{D_{\mathrm{m}}^{*}} .
$$

as the anisotropy of $D_{\mathrm{m}}$ is solely influenced by $\beta_{\lambda}$.

Fig. 6 presents at $T=295 \mathrm{~K}$ and $461 \mathrm{~K}$ the experimental values of $-\alpha_{\lambda}$ and $\beta_{\lambda}$ deduced from Eqs. 24 and 25 using $\chi=0.43$ and $D_{\mathrm{m}}^{*}$ values obtained in Fig. 4 adjustments (see Table 1). Fig. 6 also compares these experimental determinations to the theoretical expressions of $-\alpha_{\lambda}$ and $\beta_{\lambda}$ deduced from Eqs. 15 and 16, using the same parameters values as in Fig. 4. As expected, there is a very good agreement between the theoretical and the experimental expressions of $-\alpha_{\lambda}$ and $\beta_{\lambda}$ as a function of $H$ and $T$, within the error bar of the experiment.

For its part, the anisotropy of the Soret coefficient $S_{\mathrm{T}}$ is also mainly related to the terms $\alpha_{\lambda}$ and $\beta_{\lambda}$, which bring large contributions, larger than $S_{1}$ and $S_{1}-S_{2}$. In order to probe more precisely the influence of the terms $S_{1}$ and $S_{1}-S_{2}$, we can remark that when looking at the product $S_{\mathrm{T}} D_{\mathrm{m}}$ both $\alpha_{\lambda}$ and $\beta_{\lambda}$ contributions vanish. We obtain**:

$$
\frac{S_{\mathrm{T}}^{\vec{H}_{\perp}} D_{\mathrm{m}}^{\overrightarrow{H_{\perp}}}}{D_{\mathrm{m}}^{*}}=S_{\mathrm{T}}^{*}+\chi \frac{S_{1}}{T}
$$

\| We use here the adjusted value of $D_{\mathrm{m}}^{*}$ and not the corresponding experimental value $D_{\mathrm{m}}(H=0)$ to reduce the error bar in Fig. 6

** We use here the adjusted values of $S_{\mathrm{T}}^{*}$ and $D_{\mathrm{m}}^{*}$, and not the corresponding experimental values $S_{\mathrm{T}}(H=0)$ and $D_{\mathrm{m}}(H=0)$ to reduce the error bar in Fig. 7 

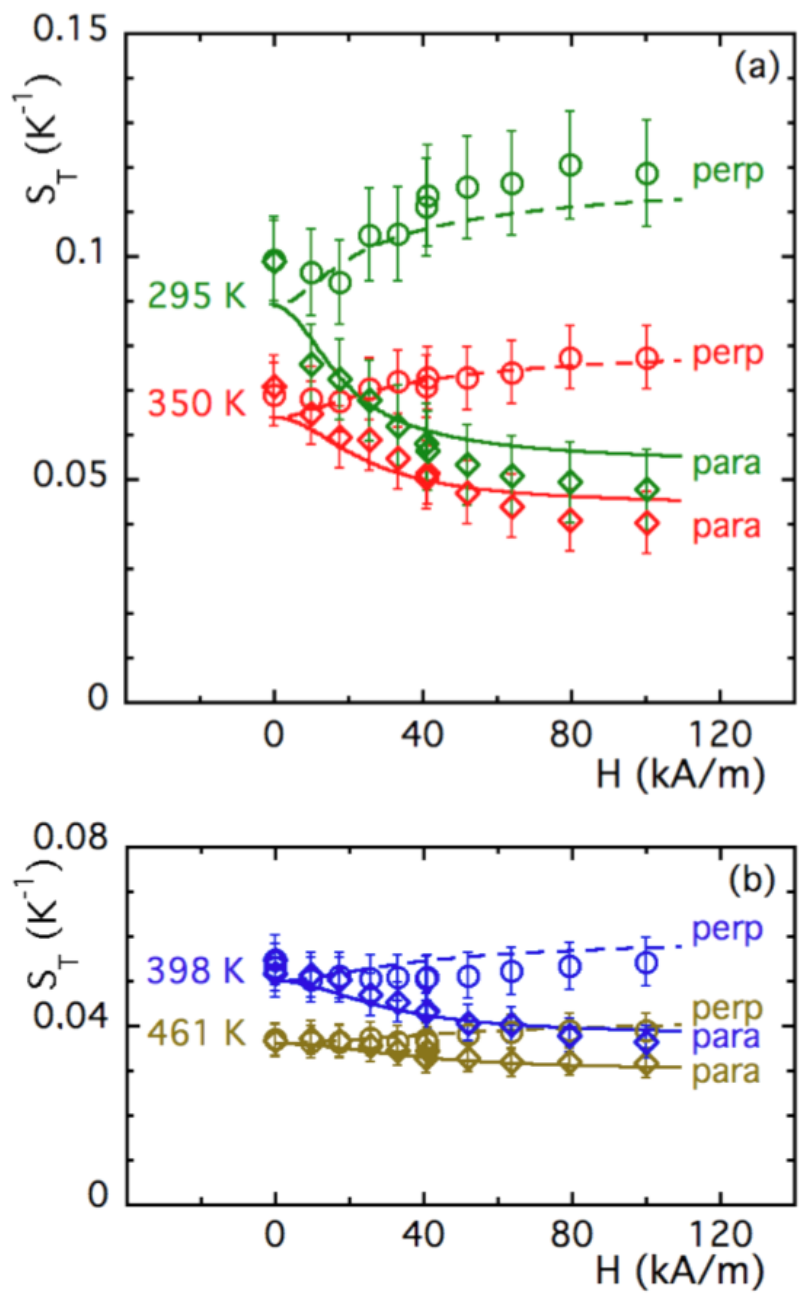

Fig. 5 Under-field Soret coefficient $S_{\mathrm{T}}$ as a function of the applied field for different temperatures $T$ (Fig. $5 \mathrm{a}$ at 295 and $350 \mathrm{~K}$, Fig. 5b at 398 and $461 \mathrm{~K}$ ); The label perp (resp. para) and open discs (resp. open diamonds) means measurements in $H_{\perp}$ direction (resp. $H_{\|}$); Symbols correspond to FRS measurements, dashed lines (resp. full lines) correspond to adjustment of the data in $H_{\perp}$ direction with Eq. 20 (resp. in $H_{\|}$direction with Eq. 21). See the text for the detailed values of the parameters used in the adjustments.

and

$$
\frac{S_{\mathrm{T}}^{\vec{H}_{\|}} D_{\mathrm{m}}^{\vec{H}_{\|}}}{D_{\mathrm{m}}^{*}}=S_{\mathrm{T}}^{*}+\chi \frac{S_{1}-S_{2}}{T} .
$$

Fig. 7 presents, at the various $T$ 's, the experimental values of $S_{\mathrm{T}}^{\vec{H}_{\perp}} D_{\mathrm{m}}^{\vec{H}_{\perp}} / D_{\mathrm{m}}^{*}$ (open discs) and $S_{\mathrm{T}}^{\vec{H}_{\|}} D_{\mathrm{m}}^{\vec{H}_{\|}} / D_{\mathrm{m}}^{*}$ (open diamonds), using $D_{\mathrm{m}}^{*}$ values obtained in Fig. 4 adjustments (see Table 1). Fig. 7 also presents the expressions $S_{\mathrm{T}}^{*}+\chi S_{1} / T$ (full lines) and $S_{\mathrm{T}}^{*}+\chi\left(S_{1^{-}}\right.$ $\left.S_{2}\right) / T$ (dotted lines), using $S_{\mathrm{T}}^{*}$ values obtained in Fig. 5 adjustments (see Table 1), $\chi=0.43$ and theoretical expressions of $S_{1}$ and $S_{2}$, given by Eqs. 28 and 29 .

The first conclusions from this representation are that here:

$$
\chi \frac{S_{1}(H, T)}{T} \ll S_{\mathrm{T}}^{*}(T)
$$
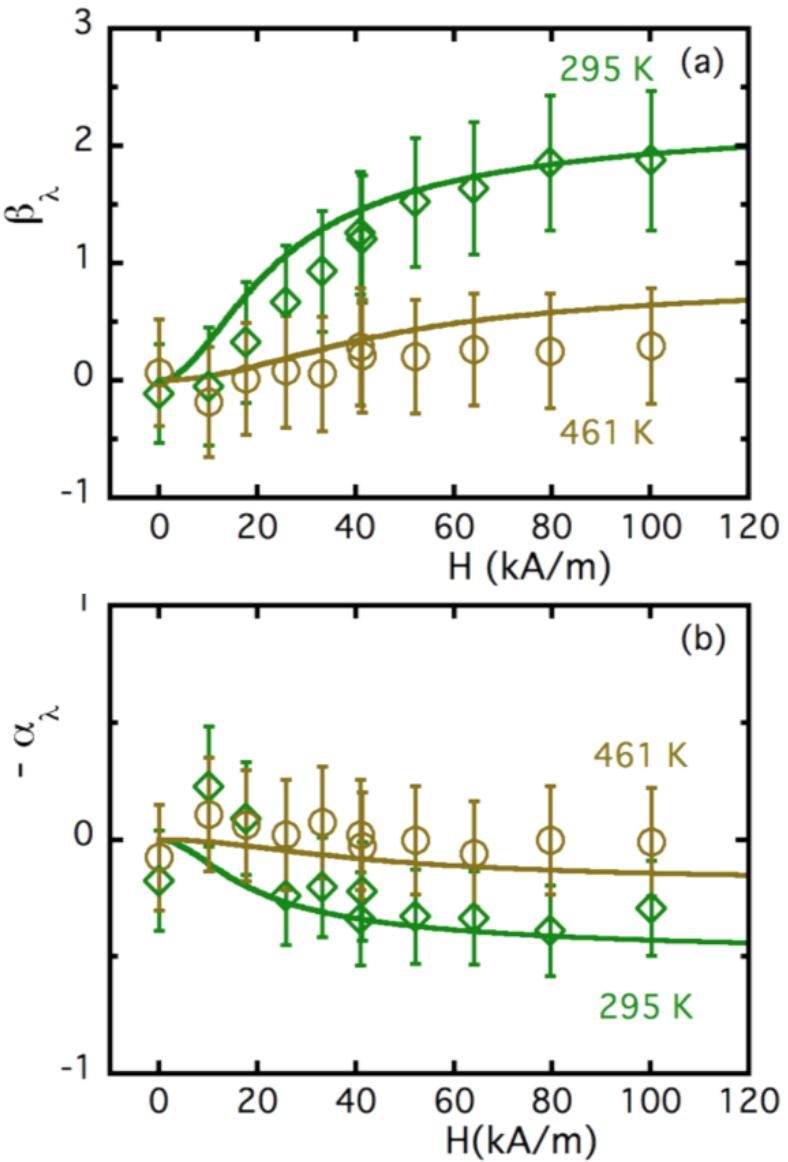

Fig. 6 Field-dependence of parameters $-\alpha_{\lambda}$ (b) and $\beta_{\lambda}$ (a) at $T=295 \mathrm{~K}$ and $461 \mathrm{~K}$. Experimental values (see text for details) are obtained from Eqs.. 24 and 25 (open diamonds at $T=295 \mathrm{~K}$; open discs at $T=461 \mathrm{~K}$ ). Theoretical adjustments (full lines) are deduced from Eqs. 15 and 16, using the same parameters values as in Fig. 4.

$$
\chi \frac{\left[S_{1}(H, T)-S 2(H, T)\right]}{T} \ll S_{\mathrm{T}}^{*}(T)
$$

which means that almost no under-field anisotropy is predicted in Eqs. 26 and 27 from a theoretical point of view, as well as a very weak field dependence of $S_{\mathrm{T}} D_{\mathrm{m}} / D_{\mathrm{m}}^{*}$, weaker than the experimental error bar.

From an experimental point of view, similar conclusions are obtained. If a subsidiary field anisotropy of $S_{\mathrm{T}} D_{\mathrm{m}} / D_{\mathrm{m}}^{*}$ is observed (mainly at $295 \mathrm{~K}$ and $350 \mathrm{~K}$ ), it however always remains smaller than the error bar. So within the error bar, which is here much larger than $\chi S_{1} / T$ and $\chi\left(S_{1}-S_{2}\right) / T$ variations, experimental values of $S_{\mathrm{T}} D_{\mathrm{m}} / D_{\mathrm{m}}^{*}$ can thus be adjusted by Eqs. 26 and 27. Then the main contribution to the under-field anisotropy of $S_{\mathrm{T}}$ is coming, as for $D_{\mathrm{m}}$, from the term $\beta_{\lambda}$, which is associated to the under-field inhomogeneities of concentration.

Note that the small shift at $H=0$ between experimental and adjusted values of $D_{\mathrm{m}}$ and $S_{\mathrm{T}}$, almost completely compensate in $D_{\mathrm{m}} S_{\mathrm{T}}$ representation of Fig. 7. It is also true for $\beta_{\lambda}$ in Fig. 6a. On the contrary the term $\alpha_{\lambda}$ in Fig. 6b, present small distorsions at very low fields. This isotropic term $\alpha_{\lambda}$, associated to the under- 

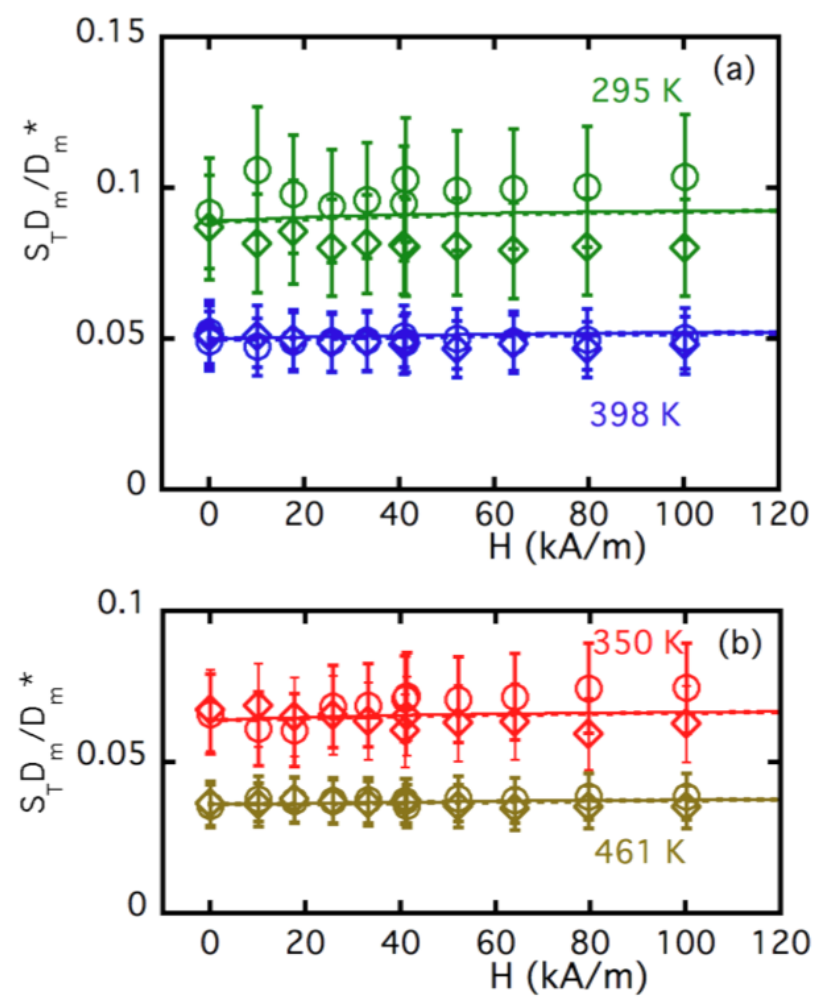

Fig. 7 Under-field anisotropy of $S_{\mathrm{T}} D_{\mathrm{m}} / D_{\mathrm{m}}^{*}$ at various $T$ 's; Experimental determinations (open discs symbols correspond to measurements in $H_{\perp}$ direction and open diamonds to measurements in $H_{\|}$direction) are compared with theoretical expressions of Eqs. 26 (full line) and 27 (dotted line) - for details see text.

field modeling of the mean-field averaged magnetic dipolar interaction, is in fact responsible for the small, but systematic, positive shift obtained between $D_{\mathrm{m}}^{*}$ and the direct experimental value of $D_{\mathrm{m}}$ in zero field at the same temperature. It is as well responsible for the negative shift obtained between $S_{\mathrm{T}}^{*}$ and the direct experimental value of $S_{\mathrm{T}}$ in zero field at the same temperature.

We propose the following explanation; In Eq. 13, contributions of magnetic dipolar interparticle interaction appear in two places, i) inside the compressibility $\chi$ measured in zero field by SAXS and SANS, through a contribution $\chi_{\text {dip }}$ (here supposed additive) and also ii) in the mean-field expression $\alpha_{\lambda}$, which equals zero in zero field. The approximation of Eq. 13 is in fact very rough in very low fields as the zero-field contribution $\chi_{\text {dip }}$ should vanish in the presence of field. Eq. 13 is thus strictly valid only in the limit of $\chi_{\text {dip }} \ll \chi$ (condition which is here verified see ahead).

At the first order, in zero field, $D_{\mathrm{m}}^{*}$ can be seen as the extrapolation of $D_{\mathrm{m}}(\vec{H})$ at $H=0$ in the absence of zero-field magnetic dipolar interaction, $D_{\mathrm{m}}^{*} \sim k T /\left[\zeta\left(\chi-\chi_{\text {dip }}\right)\right]$ while experimentally we measure $D_{\mathrm{m}}(H=0)=k T / \zeta \chi$. The conclusion is equivalent for $S_{\mathrm{T}}^{*}$; following Eq. 9, $S_{\mathrm{T}}^{*} \propto\left(\chi-\chi_{\mathrm{dip}}\right)$ and $S_{\mathrm{T}}(H=0) \propto \chi$.

We can then roughly evaluate here at $T=295 \mathrm{~K}$ the contribution $\chi_{\text {dip }}$ in zero field of the magnetic dipolar interaction to the total compressibility $\chi$ of the NPs' system to $\sim 10 \%$ of $\chi$, as $\left.\left(D_{\mathrm{m}}^{*}-D_{\mathrm{m}}(H=0)\right) / D_{\mathrm{m}}^{*} \sim\left(S_{\mathrm{T}}(H=0)-S_{\mathrm{T}}^{*}\right) / S_{\mathrm{T}}^{*}\right) \sim 10 \%: \chi_{\text {dip }} \sim+0.04$, which is of the order of magnitude of the error bar on $\chi$ measure- ments at $295 \mathrm{~K}$. This contribution would be smaller than the error bar at higher $T$ s.

\section{Conclusions}

Due to an efficient long-range ionic layering of the EMIM-TFSI anions and cations around the maghemite NPs, the present synthesized ferrofluids are stable colloids in a large domain of temperatures $T$ and applied magnetic fields $\vec{H}$, at least up to $460 \mathrm{~K}$ and $100 \mathrm{kA} \mathrm{m}^{-1}$. This stability will be very useful for their future thermoelectric applications. In zero applied field, the average interparticle repulsion is associated to a large second virial coefficient $A_{2}=7.3$, found experimentally independent of $T$. FRS measurements are performed with a fluid sample of thickness $25 \mu \mathrm{m}$ in gradients of temperature $\vec{\nabla} T$ which meet the criterion $\Delta T \ll T$ over $\sim 100 \mu \mathrm{m}$. The colloidal dispersion remains stable in presence of the temperature gradient, whatever the mean temperature $T$. The NPs always present here a positive Soret coefficient $S_{\mathrm{T}}$. The NPs are thus always migrating to the cold, as it is standardly observed in well-stabilized oily colloids $3,48,49$. NPs migrating to the hot are up to now only observed in some aqueous dispersions (based on pure water or aqueous mixtures) $47-49,51-53,55$, presumably due to the presence of hydrogen bonds in the external medium $^{102}$. Increasing $T$ lowers $S_{\mathrm{T}}$ as the NP's compressibility is decreasing, and it also increases $D_{\mathrm{m}}$, as the EMIM-TFSI viscosity decreases.

Under-field the colloidal dispersion remains here also stable in presence of the temperature gradient, whatever the mean temperature (up to $353 \mathrm{~K}$ ). $S_{\mathrm{T}}$ and $D_{\mathrm{m}}$ coefficients are anisotropic. $S_{\mathrm{T}}$ is larger when $\vec{\nabla} T$ and $\vec{\nabla} \Phi$ are perpendicular to $\vec{H}$, while $D_{\mathrm{m}}$ reduces in this configuration, which is promising for thermoelectric applications ${ }^{20}$. Their variations are well predicted by the reference theoretical model of ${ }^{54}$. The main cause of thermodiffusion anisotropy is attributed to under-field spatial inhomogeneities of NP's concentration, associated here to $\beta_{\lambda}$ coefficient in the model. In the field-direction parallel to the gradient of temperature, a Soret-induced gradient of NP's concentration, associated to spatial inhomogeneities of magnetization, appears in the fluid. According to Maxwell laws, this induces magnetic-field inhomogeneities and thus forces increasing the diffusion in the direction of the gradients.

When $T$ increases, the NP's magnetization $m_{\mathrm{S}}$ as well as the magnetic dipolar interaction parameter and $\beta_{\lambda}$ coefficient decrease, the under-field anisotropy of both $S_{\mathrm{T}}$ and $D_{\mathrm{m}}$ coefficients then drastically reduces, as it is observed in the experiment. The under-field anisotropy of $S_{\mathrm{T}}$ and $D_{\mathrm{m}}$ is well described, at the first order, by the model from ${ }^{53,54}$ applied here in the whole range of $T$ and $\vec{H}$, using the same values of the different parameters for the adjustment of both $S_{\mathrm{T}}$ and $D_{\mathrm{m}}$ at same $\vec{H}$ and $T$. Such a FF-IL in EMIM-TFSI is a good candidate for thermo-electric applications at high temperatures, which will be probed in a near future.

\section{Contributions of each of the co-authors}

M. Thiago Fiuza: PhD student in Physics shared between PHENIX - Sorbonne Univ. (SU) -France and GCF - Univ. de Brasilia (UnB) - Brazil, under the codirection of Pr J. Depeyrot - UnB and Pr R. Perzynski - SU. Involved in the SAXS and SANS measurements 
and their analysis, he performed and analyzed optical measurements with the forced Rayleigh scattering device, in particular under field.

Dr Mitradeep Sarkar: Post-doctoral fellow appointed by EU program H2020 MAGENTA in PHENIX-SU, under the responsability of Dr G. Demouchy and Pr R. Perzynski. He developed the software of the forced Rayleigh scattering device, performed measurements on the colloidal dispersions with T. Fiuza and took part in the global analysis.

Dr. Jesse C. Riedl: PhD student in Physical-Chemistry appointed by EU program H2020 MAGENTA in PHENIX-SU under the codirection of Dr E. Dubois and Dr V. Peyre, he defended his $\mathrm{PhD}$ in September 2020. He synthesized the colloidal dispersions in the Ionic Liquid and characterized them by numerous techniques, in particular their stability by SAXS and SANS, with T. Fiuza.

Pr. Andrejs Cebers: Professor in Theoretical Physics at Latvia University - Riga. He developed the model of under-field anisotropy of diffusion and Soret coefficient.

Dr. Fabrice Cousin: Engineer at C.E.A. and Member of Lab. Léon Brillouin, responsible for the SANS and SAXS devices. He was piloting SANS and SAXS measurements and has been deeply involved in the experimental analysis of the results.

Dr Gilles Demouchy: Assistant-Professor at Cergy-Pontoise Univ. - France and member of PHENIX-SU, co-responsible for the post-doc of M. Sarkar. Optical measurements on the forced Rayleigh scattering device has been performed under his supervision.

Pr. Jérome Depeyrot: Professor at Universidade de Brasilia and member of GCF-UnB, co-director of the PhD thesis of T. Fiuza, has coordinated his work on the colloidal dispersions in Ionic Liquids and the analysis of his experimental results.

Dr Emmanuelle Dubois: Director of Research at CNRS and member of PHENIX-SU, co-director the PhD work of J. C. Riedl. She has largely contributed to the synthesis of the samples and to the analysis and interpretation of the measurements, in particular for their physico-chemical aspects.

Mr Frédéric Gélébart: Engineer at CNRS and member PHENIXSU. He has developed the automatic set-up of thermalisation and magnetic field application in the forced Rayleigh scattering device.

Pr Guillaume Mériguet: Professor at Sorbonne Université and member of PHENIX-SU. He has been involved in the development of the forced Rayleigh scattering device, the development of the models and in the analysis of the results.

Pr Régine Perzynski: Professor at Sorbonne Université and member of PHENIX-UPMC, co-director of the PhD thesis of T. Fiuza and co-responsible for the post-doc of M. Sarkar. She has coordinated their work, in particular for the global analysis and the confrontation with the models.

Dr Véronique Peyre: Assistant-Professor at Sorbonne Université and member of PHENIX-SU, co-director of the PhD work of J. C. Riedl. She has been deeply involved in the synthesis and characterization of the dispersions of magnetic nanoparticles in the ionic liquid, in particular for the physico-chemical aspects.

\section{Conflicts of interest}

There are no conflicts of interest to declare.

\section{Acknowledgements}

We acknowledge funding from the Brazilian agency $\mathrm{CNPq}$, the bilateral programs PHC OSMOSE 2018 No. 40033S and CAPESCOFECUB No. Ph 959/20 and the European Union's Horizon 2020 research and innovation programme under grant agreement No. 731976 (MAGENTA). We acknowledge the Laboratoire Léon Brillouin, CEA-Saclay, France for neutron beamtime at PAXY spectrometer and especially Arnaud Hélary for technical assistance on the SANS-DLS setup.

\section{Notes and references}

1 R. Rosensweig, Ferrohydrodynamics., Cambridge University Press, Cambridge, 1985.

2 Magnetic Fluids and Applications Handbook, ed. B. Berkovsky, Begell House Inc. Publ., New-York, 1996.

3 E. Blums, A. Cēbers and M. Maiorov, Magnetic Liquids, W. de G. Gruyter, New York, 1997.

4 Ferrofluids: Magnetically Controllable Fluids and Their Applications, ed. S. Odenbach, Springer Verlag, Berlin, 2003.

5 M. Dupont, D. MacFarlane and J. Pringle, Chem. Commun., 2017, 53, 6288-6302.

6 J. He and T. Tritt, Science, 2017, 357, eaak9997.

7 A. Wurger, Phys. Rev. Research, 2020, 2, 042030 1-6.

8 X. Shi and J. He, Science, 2021, 371, 343-344.

9 D. Zhao, H. Wang, Z. U. Khan, J. C. Chen, R. Gabrielsson, M. P. Jonsson, M. Berggren and X. Crispin, Energy Environ. Sci., 2016, 9, 1450-1457.

10 H. Wang, D. Zhao, Z. U. Khan, S. Puzinas, M. P. Jonsson, M. Berggren and X. Crispin, Adv. Electron. Mat., 2017, 3, 1700013.

11 T. Li, X. Zhang, S. D. Lacey, R. Mi, X. Zhao, F. Jiang, J. Song, Z. Liu, G. Chen, J. Dai, Y. Yao, S. Das, R. Yang, R. M. Briber and L. Hu, Nat. Mater., 2019, 18, 608-613.

12 B. Yu, J. Duan, H. Cong, W. Xie, R. Liu, X. Zhuang, H. Wang, B. Qi, M. Xu, Z. L. Wang and J. Zhou, Science, 2020, 370, 342-346.

13 S. Kim, H. Lin and C. Yu, Adv. Energy Mater., 2016, 6, $16005461-7$.

14 C.-G. Han, X. Qian, Q. Li, B. Deng, Y. Zhu, Z. Han, W. Zhang, W. Wang, S.-P. Feng, G. Chen and W. Liu, Science, 2020, 368, 1091-1098.

15 M. Bonetti, N. Nakamae, B. Huang, T. J. Salez, C. WiertelGasquet and M. Roger, J. Chem. Phys., 2015, 142, 244708.

16 D. Zhao, A. Martinelli, A. Willfahrt, T. Fischer, D. Bernin, Z. U. Khan, M. Shahi, J. Brill, M. P. Jonsson, S. Fabiano and X. Crispin, Nat. Commun., 2019, 10, 1093 1-9.

17 B. Huang, M. Roger, M. Bonetti, T. J. Salez, C. WiertelGasquet, E. Dubois, R. C. Gomes, G. Demouchy, G. Mériguet, V. Peyre, M. Kouyaté, C. L. Filomeno, J. Depeyrot, F. A. Tourinho, R. Perzynski and S. Nakamae, J. Chem. Phys., 2015, 143, 054902. 
18 Z. He and P. Alexandridis, Adv. Colloid Interface Sci., 2017, 244, 54-70.

19 T. J. Salez, B. T. Huang, M. Rietjens, M. Bonetti, C. WiertelGasquet, M. Roger, C. L. Filomeno, E. Dubois, R. Perzynski and S. Nakamae, Phys. Chem. Chem. Phys., 2017, 19, 94099416.

20 T. Salez, M. Kouyaté, C. L. Filomeno, M. Bonetti, M. Roger, G. Demouchy, E. Dubois, R. Perzynski, A. Cēbers and S. Nakamae, Nanoscale Adv., 2019, 1, 2979-2989.

21 Y. Cao and T. Mu, Ind. Eng. Chem. Res., 2014, 53, 86518664.

22 D. Zhao, Z. Fei, W. H. Ang and P. J. Dyson, Small, 2006, 2, 879-883.

23 L. Rodríguez-Arco, M. T. López-López, F. González-Caballero and J. D. Durán, Journal of Colloid and Interface Science, 2011, 357, 252-254.

24 N. Jain, X. Zhang, B. S. Hawkett and G. G. Warr, ACS Applied Materials \& Interfaces, 2011, 3, 662-667.

25 C. Guibert, V. Dupuis, J. Fresnais and V. Peyre, J. Colloid Interface Sci., 2015, 453, 105-111.

26 X. Shi, W. Huang and X. Wang, Lubr. Sci., 2018, 30, 73-82.

27 J. C. Riedl, M. A. Akhavan Kazemi, F. Cousin, E. Dubois, S. Fantini, S. Loïs, R. Perzynski and V. Peyre, Nanoscale Adv., 2020, 2, 1560-1572.

28 G.-T. Wei, Z. Yang, C.-Y. Lee, H.-Y. Yang and C. R. C. Wang, J. Am. Chem. Soc., 2004, 126, 5036-5037.

29 K. Ueno, A. Inaba, M. Kondoh and M. Watanabe, Langmuir, 2008, 24, 5253-5259.

30 M. Mamusa, J. Siriex-Plénet, F. Cousin, E. Dubois and V. Peyre, Soft Matter, 2013, 10, 1097-1101.

31 M. Mamusa, J. Sirieix-Plénet, F. Cousin, R. Perzynski, E. Dubois and V. Peyre, J. Phys.: Condens. Matter, 2014, 26, 284113.

32 H. Zhang, K. Dasbiswas, N. B. Ludwig, G. Han, B. Lee, S. Vaikuntanathan and D. V. Talapin, Nature, 2017, 542, 328-331.

33 K. Bhattacharya, M. Sarkar, T. J. Salez, S. Nakamae, G. Demouchy, F. Cousin, E. Dubois, L. Michot, R. Perzynski and V. Peyre, ChemEngineering, 2020, 4, 5.

34 K. N. Marsh, J. Boxall and R. Lichtenthaler, Fluid Phase Equilibria, 2004, 219, 93-98.

35 M. D. Fayer, Chem. Phys. Lett., 2014, 616-617, 259-274.

36 K. Paduszynski and U. Domanska, J. Chem. Inf. Model., 2014, 54, 1311-1324.

37 Y. Wakizaka, $P h D$ thesis, University of Southampton - UK, 2007.

38 C. Largeot, C. Portet, J. Chmiolat, P. Taberna, Y. Gogotsi and P. Simon, J. Am. Chem. Soc., 2008, 130, 2730-2731.

39 R. Bhandary, J. G. Alauzun, P. Hesemann, A. Stocco, M. In and P. H. Mutin, Soft Matter, 2017, 13, 8023-8026.

40 Products | Solvionic, 2020, http://en.solvionic.com/ products/, Accessed: 2020-04-07.

41 Ionic Liquids in Synthesis, ed. P. Wasserscheid and T. Welton, Wiley-VCH Verlag GmbH \& Co. KGaA, Weinheim, FRG, 2002.
42 J. C. Riedl, M. Sarkar, T. Fiuza, F. Cousin, J. Depeyrot, E. Dubois, G. Mériguet, R. Perzynski and V. Peyre, (to be submitted).

43 J. K. Dhont, The Journal of Chemical Physics, 2004, 120, 1632-1641.

44 I. Chikina, S. Nakamae, V. Shikin and A. Varlamov, Entropy, 2021, 23, 150 1-10.

45 Y. Nagasaka, T. Hatakeyama, M. Osuka and A. Nagashima, Rev. Sci. Instrum., 1988, 59, 1156-1168.

46 J.-C. Bacri, A. Cēbers, A. Bourdon, G. Demouchy, B. M. Heegaard and R. Perzynski, Phys. Rev. Lett., 1995, 74, 50325035.

47 A. Mezulis, M. Maiorov and E. Blums, J. Magn. Magn. Mat., 2002, 252, 221-223.

48 S. Alves, G. Demouchy, A. Bée, D. Talbot, A. Bourdon and A. M. Figueiredo Neto, Philosophical Magazine, 2003, 83, 2059-2066.

49 G. Demouchy, A. Mezulis, A. Bée, D. Talbot, J. Bacri and A. Bourdon, J. Phys. D: Appl. Phys., 2004, 37, 1417-1428.

50 H. Ning and S. Wiegand, J. Chem. Phys., 2006, 125, 221102 $1-4$.

51 H. Ning, J. Dhont and S. Wiegand, Langmuir, 2008, 24, 2426-2432.

52 M. Sarkar, J. C. Riedl, G. Demouchy, F. Gélébart, G. Mériguet, V. Peyre, E. Dubois and R. Perzynski, Eur. Phys. J. E, 2019, 42, 979-2989.

53 M. Kouyaté, C. Filomeno, G. Demouchy, G. Mériguet, S. Nakamae, V. Peyre, M. Roger, A. Cēbers, J. Depeyrot, E. Dubois and R. Perzynski, Phys. Chem. Chem. Phys., 2019, 21, 1895-1903.

54 T. Salez, S. Nakamae, R. Perzynski, G. Mériguet, A. Cēbers and M. Roger, Entropy, 2018, 20, 405.

55 R. Cabreira-Gomes, A. da Silva, M. Kouyaté, G. Demouchy, G. Mériguet, R. Aquino, E. Dubois, S. Nakamae, M. Roger, J. Depeyrot and R. Perzynski, Phys. Chem. Chem. Phys., 2018, 20, 16402-16413.

56 R. Massart, C. R. Acad. Sci. Paris, 1980, 291, 1-3.

57 R. Massart, I.E.E.E., Trans. on Magn., 1981, 2, 1247-1248.

58 E. Laux, L. Jeandupeux, S. Uhl, H. Keppner, P. P. López, P. Sanglard, E. Vanoli and R. Marti, Mater. Today Proc., 2019, 8, 672-679.

59 C. Filomeno, M. Kouyaté, V. Peyre, G. Demouchy, A. Campos, R. Perzynski, F. Tourinho and E. Dubois, J. Phys. Chem. C, 2017, 121, 5539-5550.

60 C. Filomeno, M. Kouyaté, F. Cousin, G. Demouchy, E. Dubois, L. Michot, G. Mériguet, R. Perzynski, V. Peyre, J. SirieixPlénet and F. Tourinho, J. Magn. Magn. Mat., 2017, 431, 2-7.

61 N. Carnahan and K. Starling, J. Chem. Phys., 1970, 53, 600.

62 J.-C. Bacri, R. Perzynski, D. Salin, V. Cabuil and R. Massart, J. Magn. Magn. Mat., 1990, 85, 27-32.

63 R. G. Horn, D. F. Evans and B. W. Ninham, Journal of Physical Chemistry, 1988, 92, 3531-3537.

64 R. Hayes, G. G. Warr and R. Atkina, Phys. Chem. Chem. Phys., 
2010, 12, 1709-1723.

65 H.-W. Cheng, P. Stock, B. Moeremans, T. Baimpos, X. Banquy, F. U. Renner and M. Valtiner, Adv. Mater. Interfaces, 2015, 1500159.

66 M. Mezger, H. Schröder, H. Reichert, S. Schramm, J. S. Okasinski, S. Schöder, V. Honkimäki, M. Deutsch, B. M. Ocko, J. Ralston, M. Rohwerder, M. Stratmann and H. Dosch, Science, 2008, 322, 424-428.

67 J. Vatamanu, O. Borodin and G. D. Smith, J. Am. Chem. Soc., 2010, 132, 14825-14833.

68 C. Merlet, B. Rotenberg, P. A. Madden and M. Salanne, Phys. Chem. Chem. Phys., 2013, 15, 15781.

69 V. Ivaništšev, S. O'Connor and M. Fedorov, Interface Mag., 2014, 23, 65-69.

70 S. W. Coles, A. M. Smith, M. V. Fedorov, F. Hausen and S. Perkin, Faraday Discuss., 2018, 206, 427-442.

71 G. Feng, R. Qiao, J. Huang, S. Dai, B. G. Sumpterb and V. Meunierc, Phys. Chem. Chem. Phys., 2011, 13, 1152-1161.

72 V. Kamysbayev, V. Srivastava, N. B. Ludwig, O. J. Borkiewicz, H. Zhang, J. Ilavsky, B. Lee, K. W. Chapman, S. Vaikuntanathan and D. V. Talapin, ACS Nano, 2019, 13, 57605770.

73 A. A. Lee, C. Perez-Martinez, A. Smith and S. Perkin, Phys. Rev. Lett., 2017, 119, 026002 1-5.

74 C. F. W. Ludwig, Sitzungsberichte der Akad. der Wissenschaften Math. Klasse, 1856, 20, 539.

75 C. Soret, Arch. Sci. Phys. Nat. Genève, 1879, 3, 48.

76 S. Seki, S. Tsuzuki, K. Hayamizu, Y. Umebayashi, N.Serizawa, K.Takei and H. Miyashiro, J. Chem. Eng. Data, 2012, 57, 221-2216.

77 D. A. G. Bruggeman, Ann. Phys., 1935, 416, 636-664.

78 D. Zablotsky, PhD thesis, Faculty of Physics and Mathematics - Univ. of Latvia, Riga - Latvia, 2012.

79 D. Zablotsky, A. Mezulis and E. Blums, C. R. Mec., 2013, 341, 449-454.

80 W. Luo, T. Du and J. Huang, Phys. Rev. Lett., 1999, 82, 41344137.

81 G. K. Batchelor, J. Fluid Mech., 1982, 119, 379-408.

82 E. Blums, S. Odenbach, A. Mezulis and M. Maiorov, Phys. Fluids, 1998, 10, 2155-2163.

83 E. Blums, J. Magn. Magn. Mat., 2005, 289, 246-249.

84 L. Sprenger, A. Lange and S. Odenbach, Phys. Fluids, 2014, 26, 022001.

85 J. C. Bacri, A. Cēbers, A. Bourdon, G. Demouchy, B. M. Heegaard, B. Kashevsky and R. Perzynski, Phys. Rev. E, 1995, 52, 3936-3942.
86 G. Mériguet, E. Dubois, M. Jardat, A. Bourdon, G. Demouchy, V. Dupuis, B. Farago, R. Perzynski and P. Turq, J. Phys. Cond. Matter, 2006, 18, S2685-S2696.

87 G. Mériguet, F. Cousin, E. Dubois, F. Boué, A. Cēbers, B. Farago and R. Perzynski, J. Phys. Chem. B, 2006, 110, 4378-4386.

88 F. Gazeau, F. Boué, E. Dubois and R. Perzynski, J. Phys. Cond. Matt, 2003, 15, S1305-S1334.

89 G. Mériguet, E. Wandersman, E. Dubois, A. Cēbers, J. de Andrade Gomes, G. Demouchy, J. Depeyrot, A. Robert and R. Perzynski, Magnetohydrodynamic, 2012, 48, 415-426.

90 A. O. Ivanov and O. B. Kuznetsova, Phys. Rev. E, 2001, 64, 041405.

91 K. I. Morozov and A. V. Lebedev, J. Magn. Magn. Mat., 1990, 85,51 .

92 L. Landau and E. Lifshitz, electrodynamics of Continuous Media, Oxford, New Yok Pergamon Press, 1960.

93 E. Wandersman, E. Dubois, F. Cousin, V. Dupuis, G. Mériguet, R. Perzynski and A. Cēbers, Europhysics Lett., 2009, 86, 10005 1-5.

94 Magnetic oxides in geomagnetism" by K.M. Creer and I.G. Hedley and W. O'Reilly p.649-688 in "Magnetic oxides", ed. D. Craik, J. Wiley, London, 1975.

95 Properties and behaviour of iron oxides as determined by Mössbauer spectroscopy by E. Murad p. 309-350 in "The Geobiochemical Cycle of Iron in Iron in Soils and Clay Minerals ", ed. J. Stucki, B. Goodman and U. Schwertmann, D. Reidel Publishing Company, Dordrecht, Holland, 1988.

96 E. Tronc, D. Fiorani, M. Nogues, A. M. Testa, F. Lucari, F. D'Orazio, J. M. Greneche, W. Wernsdorfer, N. Galvez, C. Chaneac, D. Mailly and J. P. Jolivet, J. Magn. Magn. Mat., 2003, 262, 6.

97 B. Cullity and C. Graham, Introduction to Magnetic Materials, John Wiley and sons, Inc. - IEEE Press, Hoboken, New Jersey, USA, 2nd edn, 2009.

98 R. Kodama, J. Magn. Magn. Mat., 1999, 200, 359-272.

99 X. Battle and A. Labarta, J. Phys. D: Appl. Phys., 2002, 35, R15-R42.

100 R. Aquino, J. Depeyrot, M. H. Sousa, F. A. Tourinho, E. Dubois and R. Perzynski, Phys. Rev. B, 2005, 72, 184435 $1-10$.

101 F. G. da Silva, J. Depeyrot, A. Campos, R. Aquino, D. Fiorani and D. Peddis, J. of Nanosci. Nanotechnol., 2019, 19, 48884902.

102 D. Niether and S. Wiegand, J. Phys.: Condens. Matter, 2019, 31, 503003 1-25. 